BMJ Open

Diabetes

Research

\& Care

\section{Real-world evidence of glycemic control among patients with type 2 diabetes mellitus in India: the TIGHT study}

To cite: Borgharkar SS, Das SS. Real-world evidence of glycemic control among patients with type 2 diabetes mellitus in India: the TIGHT study. BMJ Open Diab Res Care 2019;7:e000654. doi:10.1136/ bmjdrc-2019-000654

$\checkmark$ Additional material is published online only. To view please visit the journal online (http://dx.doi.org/10.1136/ bmjdrc-2019-000654).

Received 16 January 2019 Revised 27 April 2019 Accepted 22 June 2019
Check for updates

\section{(c) Author(s) (or their} employer(s)) 2019. Re-use permitted under CC BY-NC. No commercial re-use. See rights and permissions. Published by BMJ.

${ }^{1}$ Sun Pharmaceutical Industries Ltd, Mumbai, India

${ }^{2}$ Sciformix, A Covance Company, Mumbai, India

Correspondence to Dr Surendra S Borgharkar; surendra.borgharkar@ sunpharma.com

\section{ABSTRACT}

Objective To determine glycemic control in adult patients with type 2 diabetes receiving antidiabetic therapy as part of routine healthcare in India.

Research design and methods This was a retrospective analysis of cross-sectional data of patients with type 2 diabetes receiving oral hypoglycemic agents (OHAs) with or without insulin between 2015 and 2017. We assessed proportion of patients with uncontrolled glycemia and performed logistic regression to evaluate its association with various risk factors and microvascular complications. Results A total of 55639 eligible records were identified; mean age of patients was $54.31( \pm 11.11)$ years. One-third of the study population had microvascular complications, predominantly neuropathy. Nearly $76.6 \%$ of patients had uncontrolled glycated hemoglobin $(\mathrm{HbA1c}) \geq 7 \%(53 \mathrm{mmol} /$ mol); $62 \%$ of these patients had $\mathrm{HbA1c}$ between $7 \%$ and $8 \%$ (53-64 mmol/mol). Glycemic control from combination of OHAs with or without insulin varied between $14.2 \%$ and $24.8 \%$. In multivariate analysis, factors statistically associated with uncontrolled glycemia were obesity (OR: 1.15), hypertension (stage I OR: 1.65 and stage II $O R: 2.73$ ) and diabetes duration $>5$ years (OR: 1.19) $(p<0.001)$. Similarly, the odds of having any microvascular complication increased with duration of diabetes (past 1-2 years, OR: $1.67 ; 2-5$ years, OR: 2.53 ; $>5$ years, OR: $4.01 ; p<0.0001$ ), hypertension (stage I, OR: 1.18 and stage II, OR: 1.34; $p<0.05$ ) and uncontrolled HbA1C (OR: 1.28 ; $p<0.0001$ ).

Conclusions Indian population with type 2 diabetes has a high burden $(76.6 \%)$ of poor glycemic control. This study highlights the need for early implementation of optimum diabetes pharmacotherapy to maintain recommended glycemic control, thereby reducing burden of microvascular complications.

\section{INTRODUCTION}

The pandemic of diabetes mellitus has affected an estimated 451 million people worldwide in 2017 and is projected to affect 693 million people by $2045 .{ }^{1}$ India has emerged as the diabetes capital in the Southeast Asian region having the highest number of people with diabetes ( 74 million), with an age-adjusted comparative prevalence of $9.8 \%$ in the age group of 18-99 years and premature mortality of $50.7 \%$ (20-79 years). ${ }^{2}$ The overall prevalence of diabetes in 15 Indian

\section{Significance of the study}

What is already known about this subject?

- India has emerged as the diabetes capital due to an interplay of modifiable and non-modifiable risk factors, but faces crucial challenges like pockets of underserved population both in urban and rural areas, lack of medical insurance, inadequate data reporting, clinical inertia and poor drug adherence-all of which are required for achieving glycemic targets.

What are the new findings?

- This study confirms the real burden of uncontrolled type 2 diabetes with a fairly large urban population across different geographies in India, concomitant with a high prevalence of microvascular complications and comorbidities like obesity and hypertension.

- Usage of newer antidiabetic class of drugs is increasing in our population; however, their impact on glycemic control could not be studied due to cross-sectional design of the study.

\section{How might these results change the focus of} research or clinical practice?

- This study highlights the need for early implementation of optimum diabetes pharmacotherapy to maintain recommended glycemic control, thereby reducing burden of microvascular complications.

states sampled in the Indian Council of Medical Research-India Diabetes (ICMR-INDIAB) population-based cross-sectional study was $7.3 \% .^{3}$ The epidemiological transition in India, in synergy with aging population and comorbid conditions such as obesity and hypertension, has played a catalyst in driving the diabetes epidemic in rural areas $(5.2 \%)$ alongside the urban ones $(11.2 \%){ }^{3}$

Indians have a 'thin-fat' phenotype (anthropometrically thin, but metabolically obese) characterized by low lean body mass and high subcutaneous fat, together with the triad of metabolic derangements (glucose and lipid dysregulation, abdominal obesity, and elevated blood pressure). This phenotype accentuates susceptibility for insulin 
resistance and development of type 2 diabetes. ${ }^{4}$ Indians have a tendency for earlier onset of type 2 diabetes, leading to an accelerated risk of developing microvascular (neuropathy, nephropathy, and retinopathy) and macrovascular complications (cardiovascular, peripheral vascular, and cerebrovascular diseases). ${ }^{5}$ However, diabetes is often diagnosed only after the disease has exacerbated to an advanced stage with microvascular complications. ${ }^{6}$ The landmark UK Prospective Diabetes Study demonstrated that a $1 \%$ reduction in glycated hemoglobin (HbAlc) by intensive hypoglycemic therapy is associated with a 37\% decrease in risk for microvascular complications. ${ }^{7}$

Most guidelines consider HbA1c $\leq 7 \%$ ( $53 \mathrm{mmol} / \mathrm{mol}$ ) as the general target of glucose control for optimum diabetes management. ${ }^{8-11}$ The Research Society for the Study of Diabetes in India has released comprehensive clinical practice recommendations for the management of type 2 diabetes, which are derived from the International Diabetes Federation Global Guideline for type 2 diabetes. ${ }^{12}$ A patient-centered approach is essential for achieving glycemic targets after considering age, body mass index (BMI), chronic kidney disease, duration of diabetes, established cardiovascular disease, financial condition, and glycemic status. ${ }^{12}$ Early initiation of a combination therapy, without undue delay of insulin, can be instrumental in achieving better glycemic targets, impeding clinical inertia, and ultimately attenuating the development of complications. ${ }^{13}$

The management of type 2 diabetes poses a unique and complex health challenge in India, where the burden is higher than that in developed countries but may be masked by inadequate reporting and substantially lower number of diabetes registries. Clinical inertia, poor drug adherence, and low disease awareness are crucial challenges for achieving glycemic targets, especially in the real-world clinical setting. ${ }^{12}{ }^{14}$ Real-world evidence can help bridge the evidence gap by providing better insights for prescribing patterns, drug adherence, comorbidities, and effects of switching or adjusting medications in the real world..$^{15}$ In 2006, the ICMR had established a multicenter clinic-based registry of diabetes with young age at onset for individuals $<25$ years. ${ }^{16}$ However, real-world data on glycemic control among adult patients from India are scarce. Hence, we conducted a large pan-India cross-sectional registry study to determine glycemic control among adult patients with type 2 diabetes mellitus, their ongoing antidiabetic therapy, and associated microvascular complications.

\section{RESEARCH DESIGN AND METHODOLOGY}

This article presents data on glycemic control from the TIGHT (The Investigation of Glycosylated Hemoglobin on Therapy in Indian diabetics) study. This was a retrospective analysis of cross-sectional data collected from over 3196 urban healthcare facilities across 26 states and union territories between 2015 and 2017. Private healthcare facilities were selected representing the north, south, east, west, and central regions. Retrospective data were collected from anonymized patient records; hence, the study was exempted from ethical clearance. Enrolled population included patients with type 2 diabetes mellitus of either gender who were on treatment with one or more oral hypoglycemic agents (OHAs) or in combination with insulin. Data of patients with type 1 diabetes and those with missing values were excluded. Protocol-defined data were transcribed on a case record form after ensuring accuracy and completeness.

The study was primarily designed to determine the proportion of patients with type 2 diabetes across the country with or without glycemic control after receiving antidiabetic treatment. Demographic and clinical factors including microvascular complications and therapeutic options associated with optimal glycemic control were also explored. The optimal glycemic control in non-pregnant adults was defined as $\mathrm{HbAlc}<7 \%(53 \mathrm{mmol} / \mathrm{mol})$; uncontrolled diabetes $\mathrm{HbAlc} \geq 7 \% \quad(53 \mathrm{mmol} / \mathrm{mol})$; fasting blood glucose (FBG) $\leq 130 \mathrm{mg} / \mathrm{dL}(7.2 \mathrm{mmol} / \mathrm{L})$, FBG $>130 \mathrm{mg} / \mathrm{dL} \quad(7.2 \mathrm{mmol} / \mathrm{L}) ;$ and post-prandial blood glucose (PPG) $<180 \mathrm{mg} / \mathrm{dL}(10.0 \mathrm{mmol} / \mathrm{L})$, PPG $\geq 180 \mathrm{mg} / \mathrm{dL}(10.0 \mathrm{mmol} / \mathrm{L})$ according to the Standards of Medical Care in Diabetes by the American Diabetes Association (ADA) 2018. ${ }^{8}$ Blood pressure (mm Hg) was categorized as normal (systolic blood pressure (SBP) $<120 \mathrm{~mm} \mathrm{Hg}$ and diastolic blood pressure (DBP) $<80 \mathrm{~mm} \mathrm{Hg}$ ), prehypertension ( $\mathrm{SBP}=120-139 \mathrm{~mm} \mathrm{Hg}$ or $\mathrm{DBP}=80-89 \mathrm{~mm} \mathrm{Hg}$ ), stage I hypertension $(\mathrm{SBP}=140$ $159 \mathrm{~mm} \mathrm{Hg}$ or $\mathrm{DBP}=90-99 \mathrm{~mm} \mathrm{Hg}$ ), and stage II hypertension ( $\mathrm{SBP} \geq 160 \mathrm{~mm} \mathrm{Hg}$ or $\mathrm{DBP} \geq 100 \mathrm{~mm} \mathrm{Hg}$ ) ${ }^{17} \mathrm{BMI}$ was classified according to the consensus statement for diagnosis of obesity, abdominal obesity, and the metabolic syndrome for Asian Indians by Misra et al: normal BMI: $18-22.9 \mathrm{~kg} / \mathrm{m}^{2}$, overweight $23-24.9 \mathrm{~kg} / \mathrm{m}^{2}$, obese: $>25 \mathrm{~kg} / \mathrm{m}^{2}{ }^{18}$ We also examined the associations among diabetes duration, glycemic control, and microvascular complications. Diabetes duration (based on treatment period) was categorized as follows: recently diagnosed, $<1$ year since diagnosis, diagnosed in past 1-2 years, diagnosed in past 2-5 years, and diagnosed $>5$ years ago. The microvascular complications were reported as diabetic neuropathy, nephropathy, and retinopathy. For subgroup analysis, patients were categorized into one of two cohorts ( $<5$ years and $\geq 5$ years) based on the duration of diabetes. The patients were then further classified into two cohorts based on the number of antidiabetic medications ( $<3$ therapies and $\geq 3$ therapies) and glycemic control (HbAlc $<7 \%$; $53 \mathrm{mmol} / \mathrm{mol}$ and $\mathrm{HbAlc} \geq 7 \%$; $\geq 53 \mathrm{mmol} / \mathrm{mol}$ ). The following parameters were assessed for each patient cohort: age, gender, BMI, hypertension, FBG, PPG, and microvascular complications.

\section{Data collection and statistical analysis}

Data collection included demographics, anthropometric measures, duration of type 2 diabetes, antidiabetes therapy, vital signs, laboratory results (HbAlc, fasting 
and postprandial glucose levels, and urine glucose level), comorbidities, microvascular complications, and concomitant medications. Summary statistics for quantitative variables included the number of observations (n), mean, SD, minimum, maximum, and median. Qualitative variables are presented with absolute and relative frequencies. A bivariate analysis between uncontrolled and controlled diabetes for all covariates and outcomes was performed ( $\chi^{2}$ test for categorical variables). Univariate and multivariate logistic regression were performed to evaluate the association among uncontrolled glycemic status, microvascular complications, and other factors. Statistical analyses were performed using SAS V.9.4, and p-value $<0.05$ was considered statistically significant.

\section{RESULTS}

\section{Demographic and clinical profile}

A total of 55639 eligible patient records aged $\geq 18$ years were identified between 2015 and 2017. Most patients $(53.2 \%)$ were $\leq 55$ years, and the mean $( \pm \mathrm{SD})$ age of patients was $54.31( \pm 11.11)$ years. Males accounted for $54.1 \%$ of the study population. The mean BMI of patients was $26.37( \pm 3.31) \mathrm{kg} / \mathrm{m}^{2}$; it was similar across gender (males: $26.38( \pm 3.26)$; females: $26.36( \pm 3.37)$ ). Comparable proportion of men and women were obese and overweight (males: $67.8 \%$ and $20.4 \%$; females: $66.7 \%$ and $20.4 \%$ ), respectively. Table 1 summarizes the demographic and clinical characteristics of patients having controlled or uncontrolled glycemic status. Two-thirds of patients reported having diabetes for a duration of $>2$ years (2-5 years: $29.9 \%$ and $>5$ years: $37.6 \%$ ). About $67.1 \%$ of patients had prehypertension, followed by stage I (25\%) and stage II hypertension (3\%) (table 1). Of the total study population, $33114(59.5 \%)$ patients were on statin therapy.

\section{Glycemic control}

The mean \pm SD HbA1c, FBG, and PPG values were 7.7\% (61 $\mathrm{mmol} / \mathrm{mol}) \pm 1.09, \quad 126.8 \mathrm{mg} / \mathrm{dL} \quad(7.03 \mathrm{mmol} / \mathrm{L}) \pm 19.02$, and $198.27 \mathrm{mg} / \mathrm{dL}(11.0 \mathrm{mmol} / \mathrm{L}) \pm 43.51$, respectively. Nearly three-fourths $(76.6 \%)$ of patients had uncontrolled $\mathrm{HbAlc} \geq 7 \%(\geq 53 \mathrm{mmol} / \mathrm{mol})$. Of patients with uncontrolled diabetes, a substantial proportion $(62 \%)$ had $\mathrm{HbAlc}$ between $7 \%$ and $8 \%(53-64 \mathrm{mmol} / \mathrm{mol})$, $33.6 \%$ had HbAlc between $8 \%$ and $10 \%(64-86 \mathrm{mmol} /$ mol), while a minor proportion $(4.4 \%)$ had $\mathrm{HbAlc}>10 \%$ (86 mmol/mol) (figure 1A). Overall, $42.4 \%$ of patients had FBG $>130 \mathrm{mg} / \mathrm{dL}(7.2 \mathrm{mmol} / \mathrm{L})$, of which $87.0 \%$ had HbAlc $\geq 7 \%(53 \mathrm{mmol} / \mathrm{mol})$. However, among patients FBG $\leq 130 \mathrm{mg} / \mathrm{dL} \quad(7.2 \mathrm{mmol} / \mathrm{L}) \quad(57.6 \%), 68.9 \%$ had $\mathrm{HbAlc} \geq 7 \%(53 \mathrm{mmol} / \mathrm{mol})$. Similarly, $62.9 \%$ of patients had PPG $>180 \mathrm{mg} / \mathrm{dL}(10.0 \mathrm{mmol} / \mathrm{L})$, of which $85.7 \%$ had $\mathrm{HbAlc} \geq 7 \%$ ( $>53 \mathrm{mmol} / \mathrm{mol})$. Among patients with PPG $<180 \mathrm{mg} / \mathrm{dL} \quad(10.0 \mathrm{mmol} / \mathrm{L}) \quad(37.1 \%), 61.0 \% \mathrm{had}$ HbAlc $\geq 7 \%$ ( $>53 \mathrm{mmol} / \mathrm{mol})$. The glycemic status had profound variations across the country, with a higher proportion of patients with type 2 diabetes having uncontrolled glycemia in Southern region (online supplemental figure 1). Of patients with obesity, $77.6 \%$ had uncontrolled HbAlc and of patients with hypertension, $81 \%$ had $\mathrm{HbAlc} \geq 7 \%(\geq 53 \mathrm{mmol} / \mathrm{mol})$. Of patients with diabetes duration $>2$ years, $\mathrm{HbA} 1 \mathrm{c}$ was under control in only $21.8 \%$ ( $2-5$ years: $22.7 \%$ and $>5$ years: $21.1 \%$ ). The effect of comorbidities like obesity and hypertension on $\mathrm{HbAlc}$ levels was exemplified in logistic regression for uncontrolled glycemia. The covariates in multivariate logistic regression included age, gender, BMI, blood pressure, disease duration, statin, number of therapies and microvascular complication. In multivariate analysis, obesity, hypertension, diabetes duration ( $\geq 2$ years), and number of therapies were statistically associated with uncontrolled glycemia (table 2).

Obese patients had significantly higher odds with OR of 1.15 (95\% CI 1.07 to 1.23) for uncontrolled glycemia compared with patients having a normal BMI $(\mathrm{p}<0.0001)$. The OR for uncontrolled diabetes status increased from stage I $(\mathrm{OR}=1.65)$ to stage II $(\mathrm{OR}=2.73)$ hypertension $(\mathrm{p}<0.0001)$. The multivariate analysis also demonstrated a significant association of uncontrolled glycemia with increasing duration of type 2 diabetes compared with recently diagnosed diabetes: past 2-5 years, OR 1.15 (95\% CI 1.06 to 1.25 ); $>5$ years, OR 1.19 (95\% CI 1.10 to 1.29 ) (table 2). The number of diabetic therapies was also significantly associated with uncontrolled glycemia (table 2).

\section{Antidiabetic therapy}

Most of the patients $(73 \%)$ were taking dual or triple therapy, followed by monotherapy (14\%), and 12\% patients were taking more than three OHAs. Insulin use was reported among $17.2 \%$ of overall patients. Of the OHAs, $83.1 \%$ were taking metformin as monotherapy or combination therapy. Multiple therapies comprised sulfonylurea + metformin pill $(60 \%)$ and combinations of different drugs including gliptins (53.1\%), alpha-glucosidase inhibitors $(15.5 \%)$, and thiazolidinediones $10 \%$. Most patients (86.6\%) diagnosed within 2 years were on metformin therapy either alone or as combination in accordance with the recent guidelines. The use of DPP-4 (dipeptidyl peptidase-4) inhibitor drugs as combination therapy increased from $47 \%$ in 2015 to about $60 \%$ in 2017. In our study population, usage of sodium-glucose cotransporter 2 (SGLT2) inhibitors as part of combination therapy was reported in about $10 \%$ of patients in the year 2017 (only $4.3 \%$ patients among the total population were under therapy). About $14 \%$ of patients were on monotherapy, while $85 \%$ were taking combination therapy. Of patients taking monotherapy, 33\% had good glycemic control as compared with $21.7 \%$ among patients on combination therapies (figure 1B). Overall, the range of glycemic control for different combinations of OHAs with or without insulin varied between $14.2 \%$ and $24.8 \%$. Irrespective of diabetes duration, patients on three or more OHAs and uncontrolled HbAlc levels had greater proportion of any microvascular complications. 
Table 1 Characteristics of patients with type 2 diabetes having controlled or uncontrolled glycemia

\begin{tabular}{|c|c|c|c|c|}
\hline & \multicolumn{4}{|l|}{ HbA1c (\%) } \\
\hline & \multirow[b]{2}{*}{ Overall } & \multirow{2}{*}{$\begin{array}{l}\text { Controlled (HbA1c <7; } \\
<53 \mathrm{mmol} / \mathrm{mol}) \\
\mathrm{n}(\%)\end{array}$} & \multirow{2}{*}{$\begin{array}{l}\text { Uncontrolled (HbA1c } \\
\geq 7 ; \geq 53 \mathrm{mmol} / \mathrm{mol}) \\
\mathrm{n}(\%)\end{array}$} & \multirow[t]{2}{*}{$P$ value } \\
\hline & & & & \\
\hline Total & 55639 & 13045 & 42594 & \\
\hline Age, mean $\pm S D$ (years) & $54.31 \pm 11.11$ & $53.58 \pm 11.32$ & $54.53 \pm 11.03$ & \\
\hline$\leq 55$ & 29598 & $7247(24.48)$ & $22351(75.52)$ & $<0.0001$ \\
\hline $56-65$ & 17037 & $3832(22.49)$ & $13205(77.51)$ & \\
\hline$>65$ & 9004 & $1966(21.83)$ & 7038 (78.17) & \\
\hline \multicolumn{5}{|l|}{ Gender } \\
\hline Male & 30095 & $6916(22.98)$ & $23179(77.02)$ & 0.0018 \\
\hline Female & 25124 & $6047(24.07)$ & $19077(75.93)$ & \\
\hline \multicolumn{5}{|l|}{ Diabetes duration } \\
\hline Recently diagnosed & 6174 & $1749(28.33)$ & $4425(71.67)$ & $<0.0001$ \\
\hline Past $1-2$ years & 10375 & $2722(26.24)$ & $7653(73.76)$ & \\
\hline Past $2-5$ years & 16635 & $3771(22.67)$ & $12864(77.33)$ & \\
\hline$>5$ years & 20920 & $4405(21.06)$ & $16515(78.94)$ & \\
\hline Any microvascular complication & 19849 & $3894(19.62)$ & $15955(80.38)$ & $<0.0001$ \\
\hline Neuropathy & 14966 & 3069 (20.51) & $11897(79.49)$ & $<0.0001$ \\
\hline Nephropathy & 4759 & 805 (16.92) & 3954 (83.08) & $<0.0001$ \\
\hline Retinopathy & 3964 & $628(15.84)$ & $3336(84.16)$ & $<0.0001$ \\
\hline $\mathrm{BMI}^{*}\left(\mathrm{~kg} / \mathrm{m}^{2}\right)$, mean $\pm \mathrm{SD}$ & $26.37 \pm 3.31$ & $26.13 \pm 3.35$ & $26.44 \pm 3.3$ & \\
\hline Normal & 6867 & 1805 (26.29) & $5062(73.71)$ & $<0.0001$ \\
\hline Overweight & 11332 & $2859(25.23)$ & $8473(74.77)$ & \\
\hline Obese & 37440 & 8381 (22.39) & $29059(77.61)$ & \\
\hline \multicolumn{5}{|l|}{ Blood pressure $+(\mathrm{mm} \mathrm{Hg})$} \\
\hline Normal & 2651 & $812(30.63)$ & 1839 (69.37) & $<0.0001$ \\
\hline Prehypertension & 37386 & $9270(24.8)$ & $28116(75.2)$ & \\
\hline Stage I hypertension & 13943 & 2735 (19.62) & $11208(80.38)$ & \\
\hline Stage II hypertension & 1658 & $228(13.75)$ & $1430(86.25)$ & \\
\hline $\mathrm{FBG}(\mathrm{mg} / \mathrm{dL}) \neq$, mean $\pm \mathrm{SD}$ & $126.8 \pm 19.02$ & $118.24 \pm 18.45$ & $129.42 \pm 18.41$ & \\
\hline$F B G \leq 130$ & 32025 & 9967 (31.12) & $22058(68.88)$ & $<0.0001$ \\
\hline $\mathrm{FBG}>130$ & 23614 & 3078 (13.03) & $20536(86.97)$ & \\
\hline PPG $(\mathrm{mg} / \mathrm{dL}) \S$, mean $\pm \mathrm{SD}$ & $198.27 \pm 43.51$ & $176.92 \pm 34.02$ & $204.81 \pm 44$ & \\
\hline$P P G<180$ & 20663 & 8055 (38.98) & 12608 (61.02) & $<0.0001$ \\
\hline$P P G \geq 180$ & 34976 & $4990(14.27)$ & $29986(85.73)$ & \\
\hline
\end{tabular}

Percentages are based on the overall counts. Hence, they may not add to $100 \%$ due to the presence of missing responses.

${ }^{*} \mathrm{BMI}\left(\mathrm{kg} / \mathrm{m}^{2}\right)$ : normal BMl: 18.0-22.9; overweight: 23.0-24.9; obese: $>25$.

†Blood pressure $(\mathrm{mm} \mathrm{Hg})$ : normal (SBP $<120$ and DBP $<80$ ), prehypertension (SBP=120-139 or DBP=80-89), stage I hypertension ( $\mathrm{SBP}=140-159$ or $\mathrm{DBP}=90-99)$, stage II hypertension (SBP $\geq 160$ or $\mathrm{DBP} \geq 100$ ).

\#FG $(\mathrm{mg} / \mathrm{dL}): \mathrm{FBG} \leq 130,7.2 \mathrm{mmol} / \mathrm{L}$ and $\mathrm{FBG}>130,7.2 \mathrm{mmol} / \mathrm{L}$.

$\S P P G(\mathrm{mg} / \mathrm{dL}): P P G<180,10 \mathrm{mmol} / \mathrm{L}$ and $P P G \geq 180,10 \mathrm{mmol} / \mathrm{L}$.

BMI, body mass index; DBP, diastolic blood pressure; FBG, fasting blood glucose; HbA1c, glycated hemoglobin; PPG, post-prandial blood glucose; SBP, systolic blood pressure.

\section{Microvascular complications}

About $35.7 \%$ of the patients had at least one microvascular complication; the proportion was higher for neuropathy $(26.9 \%)$, followed by nephropathy $(8.6 \%)$ and retinopathy $(7.1 \%)$; and $15.4 \%$ patients had two or more complications. Overall, $80.4 \%$ of patients with any microvascular complication had uncontrolled diabetes status (table 1). The proportion of patients with microvascular complications progressively increased with duration of diabetes, especially neuropathy showing a steep rise compared with nephropathy and retinopathy (figure 2). 

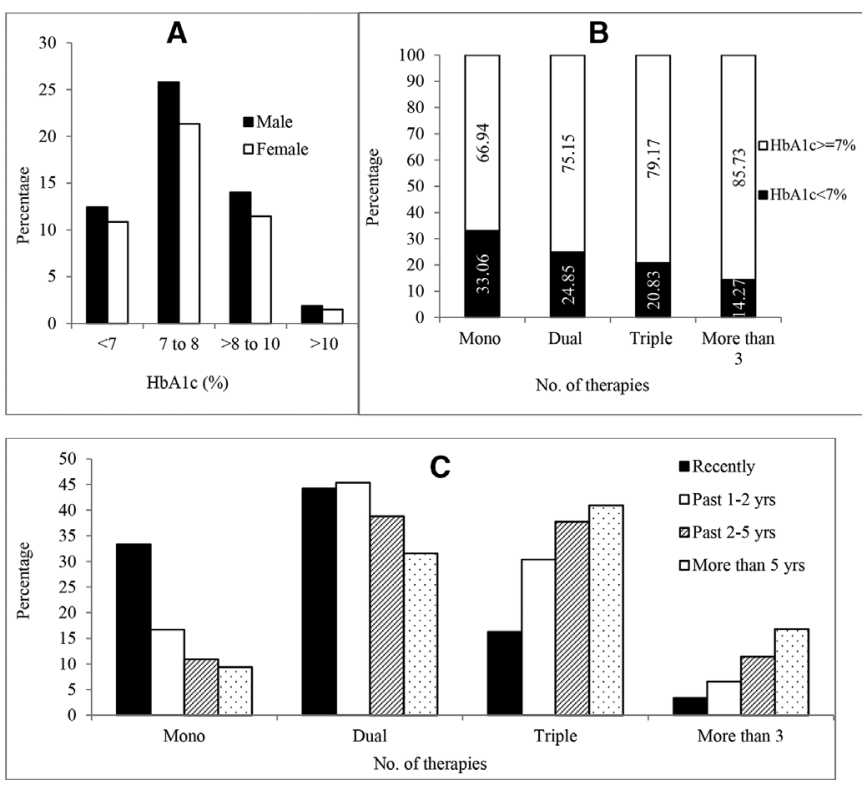

Figure 1 (A) Percentage of patients with glycated hemoglobin $(\mathrm{HbA} 1 \mathrm{c})$ categories showing glycemic control status of study population grouped by gender. (B) $\mathrm{HbA1c}$ status and number of hypoglycemic therapies used (dual, triple, and more than three therapies include patients with or without insulin). (C) Percentage of patients with different duration of diabetes grouped by number of hypoglycemic therapies.

In the univariate analysis, older age ( $>65$ years), male gender, obesity, hypertension, longer diabetes duration, and poor HbA1c control were predominant factors associated with increased risk of any microvascular complication $(\mathrm{p}<0.001) \quad$ (table 2$)$. The multivariate analysis demonstrated increasing odds of having any microvascular complication with longer duration of type 2 diabetes compared with recently diagnosed diabetes (past $1-2$ years, OR 1.67 (95\% CI 1.52 to 1.84 ); past $2-5$ years, OR 2.53 (95\% CI 2.31 to 2.78 ); >5 years, OR 4.01 (95\% CI 3.66 to 4.39)). Furthermore, patients with hypertension (stage I OR=1.18 and stage II $\mathrm{OR}=1.34 ; \mathrm{p}<0.05$ ) and uncontrolled HbAlc (OR=1.28, $\mathrm{p}<0.0001)$ had significantly increased risk of any microvascular complication (table 2). Additionally, the multivariate analysis assessing risk factors specifically for neuropathy, nephropathy, and retinopathy showed that the odds were significantly higher among patients with uncontrolled HbAlc; neuropathy $(\mathrm{OR}=1.15)$, nephropathy $(\mathrm{OR}=1.38)$, and retinopathy $(\mathrm{OR}=1.47) \quad(\mathrm{p}<0.0001)$ (online supplemental table S1).

\section{DISCUSSION}

This nationally representative cross-sectional study assessed the glycemic control in a very large urban sample of Indian adults with type 2 diabetes between 2015 and 2017 and explored the patterns of antidiabetic medication use. Our study results demonstrate the realworld burden of uncontrolled diabetes in India with only $23.4 \%$ of the study population reporting a good glycemic control $(\mathrm{HbA} 1 \mathrm{c}<7 \%$; $53 \mathrm{mmol} / \mathrm{mol})$ with mean HbA1c of $7.7 \% \pm 1.09$. Similar results for glycemic control ( $\mathrm{HbAlc}<7 \% ; 53 \mathrm{mmol} / \mathrm{mol})$ were reported in recent studies from Kerala $(28.3 \%)$ and a registry database from 26 states across India (23.4\%). ${ }^{190}$ The multicentric ICMR-INDIAB phase I study $(\mathrm{N}=480)$ reported a higher $(31 \%)$ proportion of patients with glycemic control, with mean HbAlc of $9.1 \%$ (76 mmol/mol) ${ }^{21}$ Interestingly, $25.3 \%$ of patients from the ICMR-INDIAB study had HbA1c $>10 \%$ compared with $4.4 \%$ in our study. ${ }^{21}$ This variation can be attributed to the fact that the ICMR-INDIAB study determined glycemic control among self-reported patients with diabetes.

Our study results show obesity, longer duration of diabetes, hypertension, and number of therapies to be significantlyassociated with poor glycemic control. Obesity and hypertension are well-established comorbidities for diabetes; a meta-analysis of observational studies from India showed a significant association between obesity and diabetes (pooled $\mathrm{OR}=1.14,95 \%$ CI 1.04 to 1.24 ). ${ }^{22}$ Our study results showed that glycemic control becomes more difficult with increasing duration of diabetes even with the use of combination therapies, probably due to the progressive nature of diabetes. This is consistent with results from a retrospective study in China that reported $>4$ years of diabetes duration was associated with higher odds (OR=5.98, 95\% CI 4.09 to 8.75$)$ of poor glycemic control. ${ }^{23}$ The association between poor glycemic control and multiple therapies with or without insulin in our study is likely due to longer duration and disease severity. This can also be a reflection of inadequate drug adherence or clinical inertia. Furthermore, a study from India has reported a poor frequency of HbA1c monitoring among patients with diabetes. ${ }^{21}$ Self-monitoring of blood glucose level and enhancing medication adherence can be instrumental in meaningful improvements in $\mathrm{HbAlc}$ control. ${ }^{24}{ }^{25}$ Additionally, the quality of diabetes management in India varies considerably with the awareness level, attitude, and perception of physicians on diabetes care. $^{26}$

As a well-known consequence, this study also reports association of uncontrolled glycemia with the development of any microvascular complication. Nearly one-third of the population $(35.7 \%)$ had any microvascular complication, predominantly neuropathy (26.9\%), followed by nephropathy $(8.6 \%)$ and retinopathy $(7.1 \%)$. Previous studies from India have reported the prevalence of retinopathy $(10.4 \%-32.5 \%)$, neuropathy $(14.7 \%-29.2 \%)$, and nephropathy $(6.2 \%-30.2 \%)$ across healthcare facilities in north and south regions. ${ }^{27-30}$ The population-based Chennai Urban Rural Epidemiology Study (CURES) reported a comparable prevalence of neuropathy $(25.7 \%)$ and nephropathy $(5.1 \%)$; however, prevalence of retinopathy $(17.5 \%)$ was much higher. ${ }^{31}$ The CURES further identified age, HbA1c, duration of diabetes, and serum triglycerides as major risk factors for the three microvascular complications. These findings are in line with the risk factors identified in our 


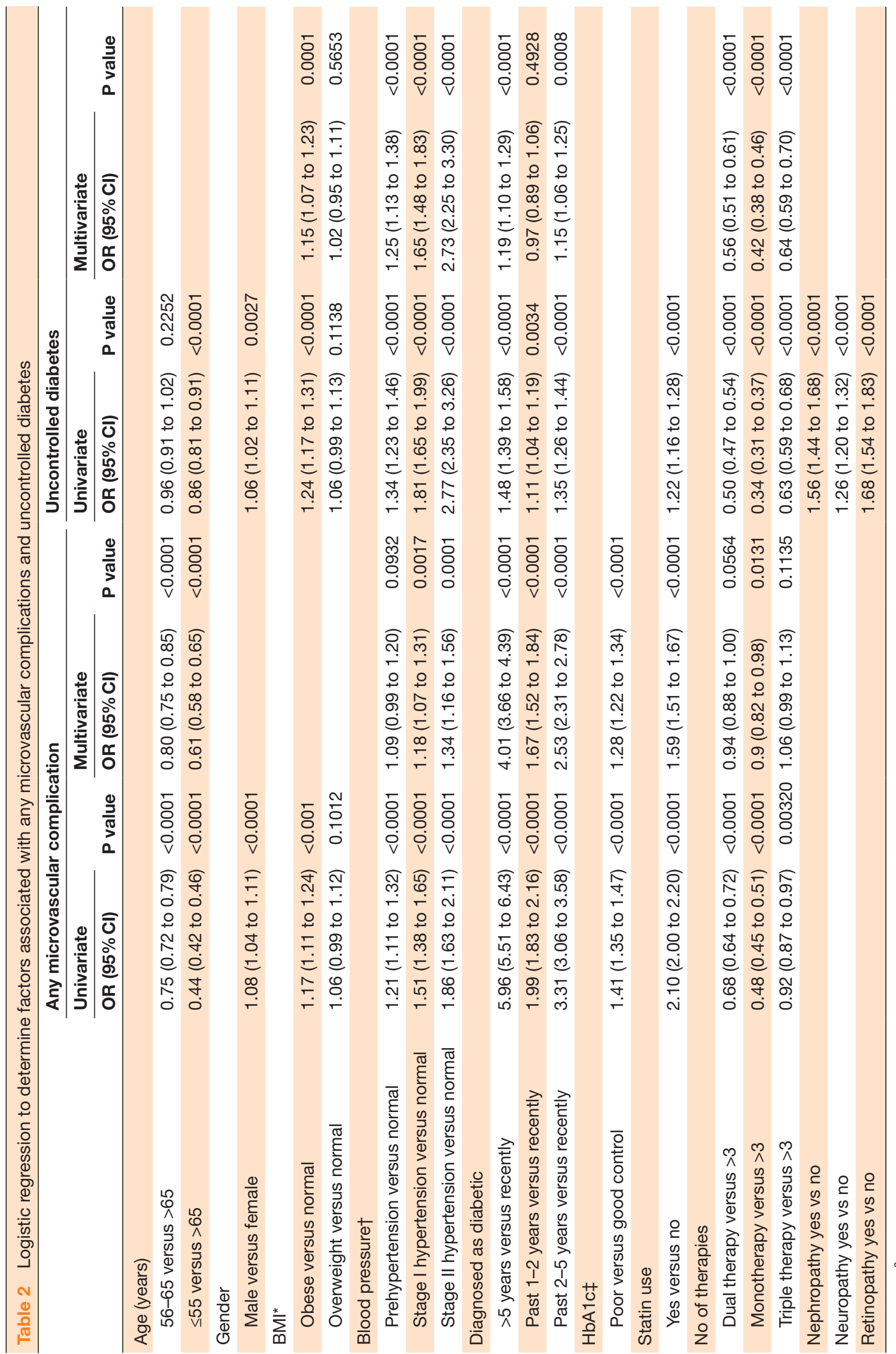

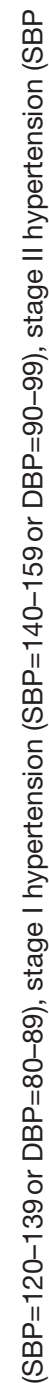




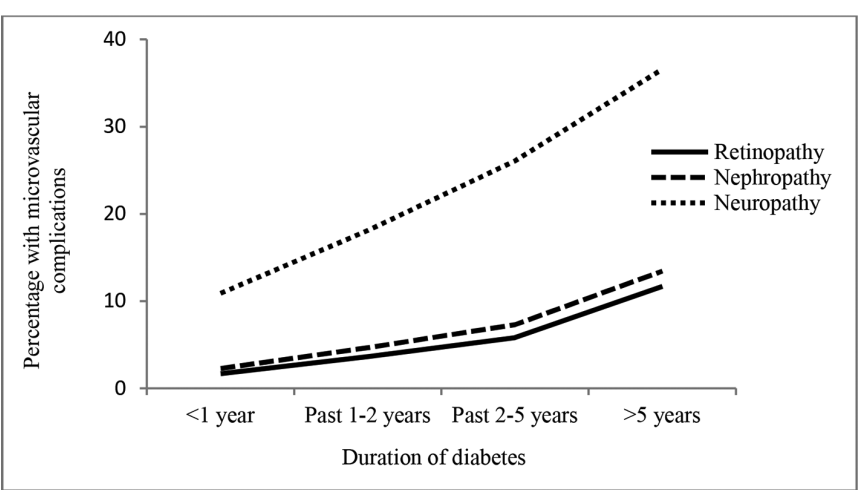

Figure 2 Duration of diabetes and various microvascular complications.

study. Stringent glycemic control remains crucial for the prevention of long-term microvascular complications. A meta-analysis from randomized controlled trials over 5 years reported that intensive glucose control compared with less intensive glucose control reduced relative risk by $20 \%$ for microvascular kidney events (HR 0.80, $\mathrm{p}<0.0001$ ) and by $13 \%$ for eye events $(\mathrm{HR}=0.87, \mathrm{p}=0.04)$, but not for nerve events $(\mathrm{HR}=0.98, \mathrm{p}=0.68) .{ }^{32}$ Additionally, in people with diabetes, early intensive glucose control therapy not only lowers blood glucose levels but also reduces blood pressure, cholesterol, and its atherogenic subfractions.

Most patients in our study (86\%) were consuming dual or multiple antidiabetic drugs, which increased with the disease duration (figure 1C). Prescription of combination therapy with metformin and newer OHAs including SGLT2 inhibitors and gliptins increased over the years. For the optimum management of type 2 diabetes, a proactive approach is recommended with individualized and early consideration of combination therapy. However, in India the stepwise approach of sequential addition of other OHAs to metformin monotherapy is often delayed. ${ }^{33}$ This results in a cascade of suboptimal glycemic control and increases the risk of microvascular and macrovascular complications. A meta-analysis demonstrated that early combination therapy with metformin compared with metformin alone leads to increase in the number of patients achieving HbAlc goal of $<7 \%$; $<53 \mathrm{mmol} / \mathrm{mol}$ (relative risk 1.40 ). ${ }^{34}$ Early insulin initiation and/or intensification among patients with inadequately controlled type 2 diabetes can also be pivotal to achieve glycemic control. ${ }^{35}$ The consensus report by the $\mathrm{ADA}$ and the European Association for the Study of Diabetes 2018 recommend using SGLT2 inhibitors or GLP-1 (glucagon-like peptide) receptor agonists for patients with diabetes having comorbidities such as chronic kidney disease or clinical heart failure, alongside consistent efforts to improve diet and exercise. ${ }^{36}$

Limitations of the study include its cross-sectional and retrospective design because of which a causal relationship between glycemic control over the course of antidiabetic therapy and development of microvascular complications could not be established. Another challenge was missing data on macrovascular complications, which made it difficult to differentiate them from comorbidities if not distinctly documented in the medical records. Additionally, it was difficult to ascertain any coronary risk from the available data on statin therapy because of lack of information on dyslipidemia control. Data on anemia were not collected; however, the patients were from private set-up and so were less likely to have anemia.

Despite the above limitations, as one of the largest realworld study on glycemic control in India, our study highlights the need for early implementation of rigorous and optimum management of diabetes to mitigate the clinical and economic burden of managing microvascular complications. Thus, the challenge of early detection, screening, and awareness will always persist, what is essential is to achieve a target glycemic control in a reasonable time frame.

\section{CONCLUSIONS}

We performed a large real-world study to determine the levels of glycemic control among patients with type 2 diabetes in India. Our study results show a high burden of uncontrolled diabetes with three-fourths of 55639 patients $(76.6 \%)$ having a poor glycemic control (HbAlc $\geq 7 \%$; $53 \mathrm{mmol} / \mathrm{mol})$. Studies like the population-based ICMR-INDIAB study have reported similar levels of glycemic control among patients with type 2 diabetes across India. Nearly one-third of our study population had microvascular complications, predominantly neuropathy. The overall usage of newer OHAs including SGLT2 inhibitors and gliptins in combination therapy increased over the years. This large real-world study highlights the need for early implementation of optimum diabetes pharmacotherapy to maintain recommended glycemic control, thereby reducing burden of microvascular complications. Enhanced awareness among patients and providers, curbing clinical inertia, individualized patient-centered therapy, together with optimal care of comorbidities like hypertension and dyslipidemia remain the mainstay of reaching glycemic targets.

\section{Research questions}

1. Can early implementation of optimum combination therapy in type 2 diabetes, including the feasibility of using newer drugs like the GLP-1 agonists and sodium-glucose cotransporter 2 (SGLT2) inhibitors reduce the burden of uncontrolled glycemia and subsequent microvascular complications?

2. Explore the utility and cost-effectiveness of newer therapies like SGLT2 inhibitors in the Indian context for reducing the incidence of chronic kidney disease and heart failure as complications of long-standing diabetes?

3. Determine whether efforts to reduce the burden of type 2 diabetes such as primordial and primary prevention prove to be more effective in Indian context rather than relying on medical therapy? 
Acknowledgements The authors thank all the physicians and doctors across India who kindly agreed to participate in the TIGHT study and extended their support for data collection (details of all the doctors are provided in the appendix section).The authors thank Piyalee Pal, Sciformix, A Covance Company, for providing medical writing support for development of the manuscript. The authors also thank Garima Joshi Sciformix, A Covance Company, for providing statistical support.

Contributors SSB contributed to the design, implementation and review of the study. SSD contributed to analysis of the results and writing of the manuscript.

Funding Development of this publication was financially supported by Sun Pharmaceutical Industries Ltd., India, through an independent medical writing grant.

Disclaimer The views and opinions described in this publication do not necessarily reflect those of the grantor.

Competing interests None declared.

Patient consent for publication Not required.

Provenance and peer review Not commissioned; externally peer reviewed.

Data availability statement All data relevant to the study are included in the article or uploaded as supplementary information.

Open access This is an open access article distributed in accordance with the Creative Commons Attribution Non Commercial (CC BY-NC 4.0) license, which permits others to distribute, remix, adapt, build upon this work non-commercially, and license their derivative works on different terms, provided the original work is properly cited, appropriate credit is given, any changes made indicated, and the use is non-commercial. See: http://creativecommons.org/licenses/by-nc/4.0/.

\section{REFERENCES}

1. Cho NH, Shaw JE, Karuranga S, et al. IDF diabetes atlas: global estimates of diabetes prevalence for 2017 and projections for 2045. Diabetes Res Clin Pract 2018;138:271-81.

2. International Diabetes Federation, 8 edition. IDF diabetes atlas, fact sheet South East Asia, 2017. Available: http://diabetesatlas.org/ resources/2017-atlas.html [Accessed 1 Aug 2018].

3. Anjana RM, Deepa M, Pradeepa R, et al. Prevalence of diabetes and prediabetes in 15 states of India: results from the ICMR-INDIAB population-based cross-sectional study. Lancet Diabetes Endocrinol 2017;5:585-96.

4. Unnikrishnan R, Gupta PK, Mohan V. Diabetes in South Asians: phenotype, clinical presentation, and natural history. Curr Diab Rep 2018;18:30.

5. Unnikrishnan R, Anjana RM, Mohan V. Diabetes mellitus and its complications in India. Nat Rev Endocrinol 2016;12:357-70.

6. Harris MI, Klein R, Welborn TA, et al. Onset of NIDDM occurs at least 4-7 yr before clinical diagnosis. Diabetes Care 1992;15:815-9.

7. Stratton IM, Adler Al, Neil HA, et al. Association of glycaemia with macrovascular and microvascular complications of type 2 diabetes (UKPDS 35): prospective observational study. BMJ 2000;321:405-12.

8. American Diabetes Association. Standards of medical care in Diabetes - 2018. Diabetes Care 2018;41(Supplement 1):S13-27.

9. Aschner P. New IDF clinical practice recommendations for managing type 2 diabetes in primary care. Diabetes Res Clin Pract 2017;132:169-70.

10. Garber AJ, Abrahamson MJ, Barzilay JI, et al. Consensus statement by the american association of clinical endocrinologists and american college of endocrinology on the comprehensive type 2 diabetes management algorithm - 2018 executive summary. Endocr Pract 2018;24:91-120.

11. ICMR diabetes guidelines, 2018. Available: https://medibulletin.com/ wp-content/uploads/2018/05/ICMR.diabetesGuidelines.2018.pdf [Accessed 3 Aug 2018].

12. Bajaj S. RSSDI clinical practice recommendations for the management of type 2 diabetes mellitus 2017. Int J Diabetes Dev Ctries 2018;38:1-115

13. Cahn A, Cefalu WT. Clinical considerations for use of initial combination therapy in type 2 diabetes. Diabetes Care 2016;39 Suppl 2:S137-S145.

14. Khunti S, Davies MJ, Khunti K. Clinical inertia in the management of type 2 diabetes mellitus: a focused literature review. $\mathrm{Br} J$ Diabetes 2015;15:65-9.
15. Edelman SV, Polonsky WH. Type 2 diabetes in the real world: the elusive nature of glycemic control. Diabetes Care 2017;40:1425-32.

16. Praveen PA, Madhu SV, Mohan V, et al. Registry of youth onset diabetes in India (YDR). J Diabetes Sci Technol 2016;10:1034-41.

17. Chobanian AV, Bakris GL, Black HR, et al. The seventh report of the joint National Committee on prevention, detection, evaluation, and treatment of high blood pressure: the JNC 7 report. JAMA 2003;289:2560-71.21.

18. Misra A, Chowbey P, Makkar BM, et al. Consensus statement for diagnosis of obesity, abdominal obesity and the metabolic syndrome for Asian Indians and recommendations for physical activity, medical and surgical management. J Assoc Physicians India 2009;57:163-70.

19. Kumar SP, Sandhya AM. A study on the glycemic, lipid and blood pressure control among the type 2 diabetes patients of North Kerala, India. Indian Heart J 2018;70:482-5.

20. Raj P, Malpani BK, Anand Moses CR, et al. The National diabetes registry in India. British Journal of Medical and Health Research 2016;3.

21. Unnikrishnan R, Anjana RM, Deepa M, et al. Glycemic control among individuals with self-reported diabetes in India--the ICMR-INDIAB Study. Diabetes Technol Ther 2014;16:596-603.

22. Babu GR, Murthy GVS, Ana Y, et al. Association of obesity with hypertension and type 2 diabetes mellitus in India: a meta-analysis of observational studies. World J Diabetes 2018;9:40-52.

23. Li J, Chattopadhyay K, Xu M, et al. Glycaemic control in type 2 diabetes patients and its predictors: a retrospective database study at a tertiary care diabetes centre in Ningbo, China. BMJ Open 2018;8:e019697.

24. Shaji S, Rajendran D, Kumpatla S, et al. Evaluation of diabetes self-care with self-monitoring of blood glucose among type 2 diabetic patients and its impact on HbA1c. Int J Diabetes Dev Ctries 2013;33:181-2.

25. Gordon J, McEwan P, Idris I, et al. Treatment choice, medication adherence and glycemic efficacy in people with type 2 diabetes: a UK clinical practice database study. BMJ Open Diabetes Res Care 2018;6:e000512.

26. Sharma SK, Seshiah V, Sahay BK, et al. Baseline characteristics of the improve control study population: a study to evaluate the effectiveness of a standardized healthcare professionals training program. Indian J Endocrinol Metab 2012;16(Suppl 2):S471-3.

27. Raman R, Ganesan S, Pal SS, et al. Prevalence and risk factors for diabetic retinopathy in rural India. Sankara Nethralaya diabetic retinopathy epidemiology and molecular genetic study III (SN-DREAMS III), report no 2. BMJ Open Diabetes Res Care 2014;2:e000005.

28. Mohan V, Shah SN, Joshi SR, et al. Current status of management, control, complications and psychosocial aspects of patients with diabetes in India: results from the DiabCare India 2011 study. Indian $J$ Endocrinol Metab 2014;18:370-8.

29. Bansal D, Gudala K, Muthyala H, et al. Prevalence and risk factors of development of peripheral diabetic neuropathy in type 2 diabetes mellitus in a tertiary care setting. J Diabetes Investig 2014;5:714-21.

30. Agrawal RPR, Ola V, Bishnoi P, et al. Prevalence of micro and macrovascular complications and their risk factors in type-2 diabetes mellitus. J Assoc Physicians India 2014;62.

31. Pradeepa R, Anjana RM, Unnikrishnan R, et al. Risk factors for microvascular complications of diabetes among South Indian subjects with type 2 diabetes--the Chennai Urban Rural Epidemiology Study (CURES) Eye Study-5. Diabetes Technol Ther 2010;12:755-61.

32. Zoungas $\mathrm{S}$, Arima $\mathrm{H}$, Gerstein $\mathrm{HC}$, et al. Effects of intensive glucose control on microvascular outcomes in patients with type 2 diabetes: a meta-analysis of individual participant data from randomised controlled trials. Lancet Diabetes Endocrinol 2017;5:431-7.

33. Joshi SR. Diabetes care in India. Ann Glob Health 2015;81:830-8.

34. Phung OJ, Sobieraj DM, Engel SS, et al. Early combination therapy for the treatment of type 2 diabetes mellitus: systematic review and meta-analysis. Diabetes Obes Metab 2014;16:410-7.

35. Al Mansari A, Obeid Y, Islam N, et al. Goal study: clinical and nonclinical predictive factors for achieving glycemic control in people with type 2 diabetes in real clinical practice. BMJ Open Diabetes Res Care 2018;6:e000519.

36. Davies MJ, D'Alessio DA, Fradkin J, et al. Management of hyperglycaemia in type 2 diabetes, 2018. A consensus report by the American Diabetes Association (ADA) and the European Association for the Study of Diabetes (EASD). Diabetologia 2018;61:2461-98. 